\title{
Establishing a normative database for quantitative pupillometry in the pediatric population
}

\author{
Sanket S. Shah ${ }^{1}$, Hantamalala Ralay Ranaivo ${ }^{2}$, Rebecca B. Mets-Halgrimson ${ }^{1,2}$, Karen Rychlik ${ }^{1,3}$ and Sudhi P. Kurup ${ }^{1,2^{*}}$
}

\begin{abstract}
Background: Pupillary evaluation is a crucial element of physical exams. Noting size, reactivity, and consensual response is critical in assessing for optic nerve dysfunction. We aim to establish normative data for scotopic pupillary size and function in the pediatric population in a clinical setting.

Methods: Pupillometry was obtained prospectively for consecutive, normal patients $<18$ years old being evaluated by Lurie Children's Ophthalmology. Quantitative data included maximum (MAX) and minimum (MIN) diameters, constriction percentage (CON), latency (LAT), average (ACV) and maximum (MCV) constriction velocities, average dilation velocity (ADV), and 75\% recovery time (T75). Iris color was noted as light, intermediate, or dark.

Results: 196 eyes of 101 participants (42.6\% male, ages 1-17 years, average age 10.3 years) were analyzed. Mean MAX was $6.6 \mathrm{~mm}(5.1-8.1 \mathrm{~mm} 95 \% \mathrm{Cl})$; MIN was $4.7 \mathrm{~mm}(3.1-6.1 \mathrm{~mm} \mathrm{95 \%} \mathrm{Cl);} \mathrm{CON} \mathrm{was} \mathrm{30 \%} \mathrm{(17-42} \mathrm{95 \%} \mathrm{Cl);} \mathrm{LAT}$ was 230 milliseconds (160-300 ms 95\% Cl); ACV was $3.70 \mathrm{~mm} / \mathrm{sec}(2.21-5.18 \mathrm{~mm} / \mathrm{sec} 95 \% \mathrm{Cl})$; and ADV was 0.88 $\mathrm{mm} / \mathrm{sec}(0.38-1.38 \mathrm{~mm} / \mathrm{sec} 95 \% \mathrm{Cl})$. Age had a positive correlation with MAX, MIN, and CON. 84.2 and $95.8 \%$ of participants showed resting pupil asymmetry of $\leq 0.5 \mathrm{~mm}$ and $\leq 1.0 \mathrm{~mm}$, respectively.
\end{abstract}

Conclusions: Quantitative pupillometry can be a useful tool for screening pediatric patients. We sought to establish normative data in this group. We found males to have significantly greater MCV and CON than females $(p<0.05)$. Also, age had a positive correlation with MAX, MIN, and CON.

Keywords: Pupillometry, Pupils, Pediatric screening, Normative

\section{Background}

The pupillary exam is a crucial element of ophthalmologic and neurologic evaluations. In particular, observation of pupillary size, reactivity, and consensual response is critical in the assessment of optic nerve dysfunction. In the early 1990's, some studies showed pupillometry as a more sensitive method to measure autonomic nerve function in adolescents with type 1 diabetes compared

\footnotetext{
* Correspondence: SKurup@luriechildrens.org

'Department of Ophthalmology, Northwestern University Feinberg School of Medicine, Chicago, IL, USA

${ }^{2}$ Division of Ophthalmology, Ann \& Robert H. Lurie Children's Hospital of Chicago, Chicago, IL, USA

Full list of author information is available at the end of the article
}

to cardiovascular reflexes [1-3]. More recently, quantitative pupillometry has been used to evaluate early changes in intracranial pressure in patients with head injury or neurological disorders $[4,5]$. It has also permitted researchers to detect deficits in patients with preperimetric glaucoma and diabetes without retinopathy $[6,7]$. Furthermore, Kardon et al. showed that chromatic pupillometry could be used by clinicians as a noninvasive method of monitoring retinal functional status, especially in patients with severe retinitis pigmentosa [8]. Quantitative pupillometry has been shown in the intensive care unit to be more accurate, consistent, sensitive, and specific with less interrater disagreement than manual

C C The Author(s). 2020 Open Access This article is licensed under a Creative Commons Attribution 4.0 International License, which permits use, sharing, adaptation, distribution and reproduction in any medium or format, as long as you give appropriate credit to the original author(s) and the source, provide a link to the Creative Commons licence, and indicate if changes were made. The images or other third party material in this article are included in the article's Creative Commons licence, unless indicated otherwise in a credit line to the material. If material is not included in the article's Creative Commons licence and your intended use is not permitted by statutory regulation or exceeds the permitted use, you will need to obtain permission directly from the copyright holder. To view a copy of this licence, visit http://creativecommons.org/licenses/by/4.0/. The Creative Commons Public Domain Dedication waiver (http://creativecommons.org/publicdomain/zero/1.0/) applies to the data made available in this article, unless otherwise stated in a credit line to the data. 
measurement by nurses experienced in neurological examinations [9]. Furthermore, Couret et al. showed that trained nurses in Neuro Critical Care Units did not detect $50 \%$ of anisocoria and concluded that automated quantitative pupillometry is a more reliable method with which to collect pupillary measurements at the bedside [10]. Several studies have described normative values $[4,5,11]$ for pupillary function in a pediatric population as measured in ambient light conditions. Kohnen et al. published a normative study [12] with scotopic pupil size. This suggests a need for normative values, measured in a clinical setting, in a pediatric population that can be used not only for evaluating patients when suspicious of disease, but also as a more accurate and sensitive screening tool. A normative database with which to compare measured patient quantitative pupillometry values can permit providers of all levels to easily examine and quickly refer patients to eye care providers in necessary situations. The present study aims to establish a normative database for scotopic pupillary size and function in children as measured in a clinical setting.

\section{Methods}

This study was approved by the Institutional Review Board of Ann \& Robert H. Lurie Children's Hospital of Chicago (Lurie Children's) and conformed to the requirements of the United States Health Insurance Portability and Privacy Act with adherence to the tenets of the Declaration of Helsinki.

Based on the lead author's availability, pupillometry and informed consent were obtained in a prospective manner for consecutive normal patients younger than 18 years old (i.e. patients without pathology anticipated to affect pupillary function who also meet inclusion criteria) who were being evaluated at the Ophthalmology Clinic of Lurie Children's. Exclusion criteria for controls included: inability to sit for testing, developmental delay, genetic syndromes, neurologic pathology (including intracranial masses), or intraocular pathology that would affect pupillary function (e.g. uveitis, cataracts, diabetes, glaucoma, optic nerve dysfunction).

Among the 143 patients consented, 42 patients were excluded due to inability to cooperate with the exam (34), inability to perform the exam due practicalities of clinic work flow after consenting [7], or pathology found on exam [1].

Pupillometry data were measured using the handheld NeurOptics PLR-200TM Pupillometer (NeurOptics, Irvine, CA, USA). The pupillometer employs an $850 \mathrm{~nm}$ infrared illumination to collect measurements on the eye before, during, and after presentation of a full-field white light stimulus with peak wavelengths comprised of red, green, and blue. An opaque rubber interface that can be sanitized places the device in contact with the orbital rim of the eye to be measured, thus occluding outside light from entering the measured eye and allowing direct measurement. The device highlights an outline of the pupil and graphs its displacement over time with accuracy of $0.05 \mathrm{~mm}$. Data were obtained in a dark clinic room throughout regular clinic hours (8:00 AM - 5:00 $\mathrm{PM})$ to emulate routine clinical testing. Scotopic conditions were verified prior to exam by measurement of luminance of less than 2 Lumens with a luminometer (Dr.Meter ${ }^{\circ}$ LX1330B Digital Illuminance/Light Meter, Hisgadget, Union City, CA, USA) at the level of the patient's eyes. The right eye was measured first in each patient. Data from each eye exam were recorded prior to examination of the second eye. Recorded data included maximum (MAX) and minimum (MIN) diameters, constriction percentage $(\mathrm{CON})$ - the calculated percentage difference between MAX and MIN, latency (LAT), average (ACV) and maximum (MCV) constriction velocities, average dilation velocity (ADV), and $75 \%$ recovery time (T75).

Iris color was noted as light (blue), dark (brown) or intermediate. Study data were managed using REDCap electronic data capture tools hosted at Northwestern University [13].

\section{Statistical analysis}

Categorical variables are reported as frequencies, and percentages and continuous variables are reported in means and standard deviations. Pearson correlations were used to describe relationships between two continuous variables: age and eye measurements. To account for the random effect of two-eye measurements per patients, mixed effect models were run to determine differences between independent variables including eye color, race, ethnicity, and gender. All tests were twosided, and significance was defined as $p<0.05$. Statistical analyses were conducted using SAS version 9.4 (SAS Institute, Inc., Cary, NC).

\section{Results}

Data from 196 eyes of 101 participants were analyzed with the exception of average dilation velocity and $75 \%$ recovery time, which could not be measured in 62 and 94 eyes, respectively (usable $n=134$ and 102, respectively). The self-identified demographic distribution of the population is shown in Table 1.

In our study population, the mean maximum resting pupil diameter was $6.6 \pm 0.74 \mathrm{~mm}$, and the mean minimal post-stimulation diameter was $4.7 \pm 0.77 \mathrm{~mm}$. The mean percentage of reduction in pupil size after stimulation was $30 \pm 6.2 \%$. The average latency time was $230 \pm$ $34 \mathrm{~ms}$. The mean constriction velocity was $3.70 \pm 0.744$ $\mathrm{mm} / \mathrm{s}$ while the mean dilation velocity was $0.88 \pm 0.25$ $\mathrm{mm} / \mathrm{s}$. 
Table 1 Demographics of the pediatric population measured. Race and ethnicity were self-reported by the guardians of each patient

\begin{tabular}{ll}
\hline Age (years) & $10.33 \pm 3.83$ (mean \pm SD) \\
Age range (years) & $1.01-17.44$ \\
Gender & \\
Male & $42.6 \%$ \\
Female & $57.4 \%$ \\
Eye Color & \\
Blue & $9.7 \%$ \\
Brown & $78.1 \%$ \\
In Between & $12.2 \%$ \\
Race & \\
White & $31.7 \%$ \\
African American & $7.9 \%$ \\
Asian & $8.9 \%$ \\
Other & $51.5 \%$ \\
Ethnicity & \\
Hispanic & $42.6 \%$ \\
Non-Hispanic & $57.4 \%$ \\
\hline
\end{tabular}

Table 2 highlights the mean pupillometry values for across the entire population we tested and the subsets based on gender. The most commonly encountered iris color was dark ( $n=133$ out of 196 eyes). Males had significantly greater constriction percentage and maximum constriction velocity than females $(p<0.05)$. There were no statistically significant differences between the parameters measured in Hispanic and non-Hispanic subjects (self-reported as ethnicity by all subjects). Race (i.e. White, African-American, Asian, other) was selfreported for 49/101 subjects, and there were no statistically significant differences shown between the parameters measured.

There was a positive correlation with age and maximum diameter $(r=0.26 p=0.0002)$, minimum diameter $(r=0.28 p<0.0001)$, and constriction percentage $(r=$ $0.23 p=0.0015)$. Without quantitative pupillometry, anisocoria has been defined as asymmetry of $1 \mathrm{~mm}$ or greater $[4,5]$. Moreover, pupil asymmetry measuring less than $0.5 \mathrm{~mm}$ is difficult to detect with the naked eye. In this study, 95 participants recorded measurements from both eyes. Of these, $84.2 \%(80 / 95)$ and $95.8 \%(91 / 95)$ of participants showed resting pupil asymmetry between 0 and $0.5 \mathrm{~mm}$ and $0-1.0 \mathrm{~mm}$, respectively.

\section{Discussion}

Previous studies have evaluated pupillary size in both ambient photopic $[4,5,11,14,15]$ and scotopic conditions [12, 14, 15]. There has also been assessment of pupillary function in ambient light conditions alone [4, $5,11]$. Table 3 shows the results of pupillary size and function from the aforementioned studies. This study is the first to propose normative values for parameters of scotopic pupillary function in a pediatric population in typical clinical conditions.

It is well established that, throughout childhood, the eye and visual pathway have significant growth and development, which may expectantly lead to pupillary changes over time. Although under ambient light conditions, Brown et al. measured data similar to our results that suggested a weak, yet statistically significant, correlation between pupil size and age (resting diameter, $r=$ 0.29 ; post-stimulus aperture, $r=0.19$ ). Other studies in light [11] and dark conditions [12] suggest a peak in pupil size around 11 years old, which was shown in light to continue to decrease throughout adulthood [16]. However, we did not see a similar peak and subsequent decrease in our scotopic pediatric data. Our contrast in findings compared to Kohnen et al. might be attributable to differences in population sampling; ours included a larger number of subjects, especially in ages above 11 years old.

In collecting pupillometry data, the device used reports data in two colors: green (reliable) and red (unreliable). It will only display as green if it generates reliable data in at least six out of the eight variables measured. This explains the discrepancies in $\mathrm{n}$ values of $\mathrm{ADV}$ and T75 from the remainder of the data. Adhikari et al. showed that pupil diameter measured by an infrared camera is affected by fixation eccentricity, introducing at least a $0.07-\mathrm{mm}$ error once eye movements deviate more than $5^{\circ}$ from the central fixation axis [17]. While fixation eccentricity was not measured in this study, the authors felt the levels of reported reliability from the pupillometer served as an appropriate surrogate when considering the nature of examining children in a clinical setting. Multiple studies $[4,11,12]$ have mentioned the inherent difficulties in measuring children younger than 5 years old. We found this to be true for practical purposes, as well; 28/42 of the patients unable to cooperate with the exam were less than 5 years old. Among these children, the most encountered difficulties were fear of the pupillometer, inconsolable crying, and constant head movement. The remaining 14/42 patients were between 5 and 10 years old. These children cooperated well with the exam, but they were unable to avoid blinking during the pupillary constriction period of measurement - thus preventing adequate data collection. With more experience, younger children were able to be distracted for sufficient periods of time to collect data, and older children tolerated assistance from the examiner's hand to prevent eye blinking. Thus, proper training and repeated use, just as with other instruments used in eye examination, 
Table 2 Quantitative pupillometry values measured under scotopic conditions during this study, reported as mean values of the population and between gender and ethnicity

\begin{tabular}{|c|c|c|c|c|c|}
\hline \multirow[b]{2}{*}{ Variable } & \multirow[b]{2}{*}{ All Children } & \multicolumn{2}{|l|}{ Gender } & \multicolumn{2}{|l|}{ Ethnicity } \\
\hline & & Male & Female & Hispanic/Latino & Non-Hispanic/Latino \\
\hline \multicolumn{6}{|l|}{ Maximum Diameter (mm) } \\
\hline Mean (n) & $6.6(196)$ & $6.7(83)$ & $6.5(113)$ & $6.5(83)$ & $6.7(113)$ \\
\hline (Mean - 2 SD, Mean + 2 SD) & $(5.1,8.1)$ & $(5.1,8.3)$ & $(5.2,7.9)$ & $(5.2,7.8)$ & $(5.1,8.2)$ \\
\hline \multicolumn{6}{|l|}{ Minimum Diameter (mm) } \\
\hline Mean (n) & $4.7(196)$ & $4.6(83)$ & $4.7(113)$ & $4.6(83)$ & $4.7(113)$ \\
\hline (Mean - 2 SD, Mean + 2 SD) & $(3.1,6.2)$ & $(3.1,6.2)$ & $(3.2,6.2)$ & $(3.2,6.0)$ & $(3.1,6.3)$ \\
\hline \multicolumn{6}{|l|}{ Constriction Percentage } \\
\hline Mean (n) & $-30(196)$ & $-31 *(83)$ & $-28^{*}(113)$ & $-29(83)$ & $-30(113)$ \\
\hline (Mean - 2 SD, Mean + 2 SD) & $(-42,-17)$ & $(-41,-21)$ & $(-42,-15)$ & $(-42,-16)$ & $(-42,-18)$ \\
\hline \multicolumn{6}{|l|}{ Latency (ms) } \\
\hline Mean (n) & $230(196)$ & $230(83)$ & $230(113)$ & $230(83)$ & $230(113)$ \\
\hline (Mean - 2 SD, Mean + 2 SD) & $(160,300)$ & $(170,290)$ & $(170,290)$ & $(170,290)$ & $(170,290)$ \\
\hline \multicolumn{6}{|c|}{ Average Constriction Velocity (mm/s) } \\
\hline Mean (n) & $-3.70(196)$ & $-3.83(83)$ & $-3.60(113)$ & $-3.69(83)$ & $-3.69(113)$ \\
\hline (Mean - 2 SD, Mean + 2 SD) & $(-5.18,-2.21)$ & $(-5.17,-2.49)$ & $(-5.16,-2.04)$ & $(-5.15,-2.23)$ & $(-5.21,-2.17)$ \\
\hline \multicolumn{6}{|c|}{ Maximum Constriction Velocity (mm/s) } \\
\hline Mean (n) & $-5.02(196)$ & $-5.28^{*}(83)$ & $-4.83 *(113)$ & $-4.91(83)$ & $-5.09(113)$ \\
\hline (Mean - 2 SD, Mean + 2 SD) & $(-6.81,-3.23)$ & $(-6.76,-3.80)$ & $(-6.73,-2.93)$ & $(-6.79,-3.03)$ & $(-6.83,-3.35)$ \\
\hline \multicolumn{6}{|l|}{ Average Dilation Velocity (mm/s) } \\
\hline Mean (n) & $0.88(134)$ & $0.91(59)$ & $0.86(75)$ & $0.87(55)$ & $0.90(79)$ \\
\hline (Mean - 2 SD, Mean + 2 SD) & $(0.38,1.38)$ & $(0.39,1.43)$ & $(0.38,1.34)$ & $(0.37,1.37)$ & $(0.44,1.36)$ \\
\hline \multicolumn{6}{|l|}{ 75\% Recovery Time (s) } \\
\hline Mean (n) & $2.82(102)$ & $2.89(45)$ & $2.77(57)$ & $2.85(47)$ & $2.80(55)$ \\
\hline (Mean - 2 SD, Mean + 2 SD) & $(1.51,4.13)$ & $(1.77,4.01)$ & $(1.33,4.21)$ & $(1.69,4.01)$ & $(1.36,4.24)$ \\
\hline \multicolumn{6}{|l|}{ Asymmetry } \\
\hline$\leq 0.5 \mathrm{~mm}$ & $84.2 \%$ & & & & \\
\hline$\leq 1.0 \mathrm{~mm}$ & $95.8 \%$ & & & & \\
\hline
\end{tabular}

$n$ Number of eyes. ${ }^{*} p<0.05$

can yield more quantitative measurements that were otherwise subjectively based. Although we presented a smaller sample size for younger individuals, we hope to provide some amount of normative comparison in that age group. Finally, for future study, a larger sample size can strengthen the significance of a normative database.

Previous studies have been equivocal on the association between gender and pupillary reaction, showing weak differences [14] or no difference at all [11]. Our data show statistical differences only between the constriction percentage and maximum constriction velocities of young males and females $(p=0.0179$ and $p=$ 0.0105 , respectively). In contrast to Fan et al., our findings might be attributable to differences in population sampling: ours having a higher $\mathrm{n}$ and lower ages than their population [14]. Our data suggest that a potentially abnormal patient should be compared to one of the same gender from our data.

Via self-reporting, demographic data was obtained for all subjects on ethnicity but for only 49/101 subjects with regards to race. There were no statistical differences for any measured variable by ethnicity or by race. However, Brown et al. measured a population that was $64 \%$ white and 24\% African American, finding statistical differences in pupil size and function (MCV and ADV) between the eyes of White and African American subjects when measure in ambient light. Due to differences in demographics between the two studies, direct comparisons cannot be made.

Anisocoria has been clinically defined as asymmetry of $1 \mathrm{~mm}$ or greater $[4,5]$. Interstimulus interval between eyes has been shown to affect measurement of pupillary 
Table 3 Quantitative pupillometry data reported by previous studies presented in comparison with this study

\begin{tabular}{|c|c|c|c|c|c|c|c|c|c|c|c|c|}
\hline Study & $n$ & Ages (years) & $\begin{array}{l}\text { Light } \\
\text { conditions }\end{array}$ & $\begin{array}{l}\text { MAX } \\
(\mathrm{mm})\end{array}$ & $\begin{array}{l}\text { MIN } \\
(\mathrm{mm})\end{array}$ & $\begin{array}{l}\text { CON } \\
(\%)\end{array}$ & $\begin{array}{l}\text { LAT } \\
\text { (ms) }\end{array}$ & $\begin{array}{l}\mathrm{ACV} \\
(\mathrm{mm} / \\
\mathrm{s}) \\
\end{array}$ & $\begin{array}{l}\mathrm{MCV} \\
(\mathrm{mm} / \mathrm{s})\end{array}$ & $\begin{array}{l}\text { ADV } \\
(\mathrm{mm} / \\
\mathrm{s})\end{array}$ & $\begin{array}{l}\text { T75 } \\
\text { (s) }\end{array}$ & Asymmetry \\
\hline $\begin{array}{l}\text { This } \\
\text { paper }\end{array}$ & $\begin{array}{l}196 \text { eyes (101 } \\
\text { patients) }\end{array}$ & $1-18$ & Scotopic & $6.6 \pm 0.08$ & $\begin{array}{l}4.7 \pm \\
0.8\end{array}$ & $\begin{array}{l}30 \% \pm \\
6 \%\end{array}$ & $\begin{array}{l}230 \pm \\
35\end{array}$ & $\begin{array}{l}3.70 \pm \\
0.75\end{array}$ & $\begin{array}{l}-5.02 \pm \\
0.90\end{array}$ & $\begin{array}{l}0.88 \pm \\
0.25\end{array}$ & $2.82 \pm 0.66$ & $\begin{array}{l}15.8 \% \geq \\
0.5 \mathrm{~mm}\end{array}$ \\
\hline $\begin{array}{l}\text { Taylor } \\
\text { et al. [5] }\end{array}$ & $\begin{array}{l}2432 \text { paired } \\
\text { measurements } \\
\text { ( } 310 \text { patients) }\end{array}$ & $1-87$ & $\begin{array}{l}\text { Ambient } \\
\text { light }\end{array}$ & $4.1 \pm 0.34$ & $\begin{array}{l}2.7 \pm \\
0.21\end{array}$ & $34 \%$ & $\begin{array}{l}240 \pm \\
40\end{array}$ & $\begin{array}{l}1.48 \pm \\
0.33\end{array}$ & & & & $\begin{array}{l}<1 \%>0.5 \\
\mathrm{~mm}\end{array}$ \\
\hline $\begin{array}{l}\text { Boev } \\
\text { et al. [4] }\end{array}$ & $\begin{array}{l}90 \text { eyes ( } 90 \\
\text { patients) }\end{array}$ & $0-18$ & $\begin{array}{l}\text { Ambient } \\
\text { light }\end{array}$ & 4.11 & 2.65 & $36 \%$ & & 2.34 & & 2.2 & & $\begin{array}{l}\text { "Normal" }< \\
0.5 \mathrm{~mm}\end{array}$ \\
\hline $\begin{array}{l}\text { Kohnen } \\
\text { et al. } \\
\text { [12] }\end{array}$ & $\begin{array}{l}166 \text { eyes (83 } \\
\text { patients) }\end{array}$ & $6.01 \pm 4.11$ & $\begin{array}{l}2 \text { min dark } \\
\text { adaptation }\end{array}$ & $6.09 \pm 0.98$ & & & & & & & & $\begin{array}{l}9.64 \% \geq \\
0.5 \mathrm{~mm}\end{array}$ \\
\hline $\begin{array}{l}\text { Brown } \\
\text { et al. } \\
{[11]}\end{array}$ & 201 eyes & $1-18$ & & $5.36 \pm 0.90$ & $\begin{array}{l}3.62 \pm \\
0.65\end{array}$ & & & & $\begin{array}{l}4.92 \\
(\mathrm{~W}) \\
4.42 \\
(\mathrm{AA})\end{array}$ & & & \\
\hline $\begin{array}{l}\text { Fan } \\
\text { et al. } \\
{[14]}\end{array}$ & 25 patients & $18-22$ & $\begin{array}{l}\text { Photopic } \\
\text { and } \\
\text { scotopic }\end{array}$ & $\begin{array}{l}5.93 \pm 0.75(\mathrm{M}, \mathrm{P}) \\
5.53 \pm 0.57(\mathrm{~F}, \mathrm{P}) \\
6.72 \pm 0.86(\mathrm{M}, \mathrm{S}) \\
6.42 \pm 0.68(\mathrm{~F}, \mathrm{~S})\end{array}$ & & & & & & & & \\
\hline $\begin{array}{l}\text { Tekin } \\
\text { et al. } \\
\text { [15] }\end{array}$ & $\begin{array}{l}20 \text { eyes ( } 20 \\
\text { patients) } \\
25 \text { eyes ( } 25 \\
\text { patients) }\end{array}$ & $\begin{array}{l}0-10 \\
11-20\end{array}$ & Scotopic & $\begin{array}{l}2.4 \pm 1.1 \\
2.4 \pm 1.1\end{array}$ & & $\begin{array}{l}55 \pm \\
7 \% \\
57 \pm \\
6 \%\end{array}$ & $\begin{array}{l}262 \pm \\
37 \\
242 \pm \\
48\end{array}$ & $\begin{array}{l}6.1 \pm \\
0.6 \\
6.2 \pm \\
1.0\end{array}$ & & $\begin{array}{l}2.4 \pm \\
1.1 \\
2.4 \pm \\
1.0\end{array}$ & & \\
\hline
\end{tabular}

$n$ Number of measurements, MAX Maximum diameter, MIN Minimum diameter, CON Constriction percentage, LAT Latency, ACV Average constriction velocity, MCV Maximum constriction velocity, $A D V$ Average dilation velocity, $T 7575 \%$ recovery time; $(M, P)$ Male, photopic, $F, P$ Female, photopic, $M, S$ Male scotopic, $F, S$ Female, scotopic, $W$ White, $A A$, African-american

light response amplitudes if the pupil has not returned to its resting diameter, and the necessary interval is shorter in scotopic conditions [18]. Order of eye measurement, thus, could affect anisocoria data if the interstimulus interval is not appropriate. During this study's data collection, the interval between eye measurements was roughly $1 \mathrm{~min}$ while the previous eye data was transcribed. There was no significant trend found in the data to favor the resting diameter of one eye to be greater than the other. As shown in Table 3, multiple studies including the present one show the majority of patients to have pupillary asymmetry of less than $0.5 \mathrm{~mm}$ on quantitative pupillometry. Therefore, the authors recommend future investigation into detection of pathology by using thresholds of $0.5 \mathrm{~mm}$ and $1 \mathrm{~mm}$ for anisocoria to determine the potential utility of quantitative pupillometry over standard subjective measurement as a screening tool as well as determining exact sensitivity, specificity, and receiver-operator curves for each method using these thresholds.

The clinical nature of this study provides both strengths and limitations to the data and analysis presented above. As mentioned earlier, fixation eccentricity and exact interstimulus interval provide a more standardized approach to data collection. Furthermore, data were collected throughout the clinic day, thus preventing consistent time measurements to limit effects from circadian rhythm on pupillary function [19]. Finally, given the clinical setting of these measurements, children are likely to have many psychosensory influences on pupil size and function such as anxiety, fright, and pain, all of which would exhibit mydriatic effects on the data. However, the authors wish to highlight that when clinically evaluating a pediatric population, precise time of day and measurements that require cooperation as well as the psychosensory effect of visiting any clinical setting whether it be in a hospital-based clinic or an outpatient clinic are rarely standard. Therefore, the data presented in this study provide a robust database with which comparisons can be made with a pediatric population in a clinical setting.

\section{Conclusion}

In conclusion, the authors offer quantitative pupillometry measurements in children to be compared against the gender-matched data presented in this manuscript. Children falling outside of normal ranges may warrant further evaluation.

\section{Abbreviations}

ACV: Average constriction velocity; ADV: Average dilation velocity;

CON: Constriction percentage; LAT: Latency; MAX: Maximum diameter; MCV: Maximum constriction velocity; MIN: Minimum diameter; NCCU: Neurocritical care unit; T75: 75\% recovery time

Acknowledgments

Not applicable. 


\section{Authors' contributions}

SS: Study design, enrollment of participants, data collection, data analysis, manuscript writing and editing. HR: Study design, data analysis, manuscript writing and editing. RMH: Study design, manuscript writing and editing. SK: Study design, manuscript writing and editing. KR: Data analysis, manuscript writing and editing. All authors have read and approved the manuscript.

\section{Funding}

This project was supported by a Children's Surgical Foundation grant (Ann \& Robert H. Lurie Children's Hospital of Chicago). The funds were used to purchase the pupillometers used for the study.

\section{Availability of data and materials}

The datasets generated and/or analysed during the current study are not publicly available because the participants did not consent to have their data available for future research.

\section{Ethics approval and consent to participate}

This study was approved by the Institutional Review Board of Ann \& Robert H. Lurie Children's Hospital of Chicago (Lurie Children's) and conformed to the requirements of the United States Health Insurance Portability and Privacy Act with adherence to the tenets of the Declaration of Helsinki. Written informed consent was obtained from the parents or guardians for participants younger than 18 years old. Written assent was also obtained from participants 12 years or older.

\section{Consent for publication}

Not applicable.

\section{Competing interests}

The authors declare that they have no competing interests.

\section{Author details}

'Department of Ophthalmology, Northwestern University Feinberg School of Medicine, Chicago, IL, USA. ${ }^{2}$ Division of Ophthalmology, Ann \& Robert H. Lurie Children's Hospital of Chicago, Chicago, IL, USA. ${ }^{3}$ Stanley Manne Children's Research Institute, Chicago, IL, USA.

Received: 27 June 2019 Accepted: 12 March 2020

Published online: 26 March 2020

\section{References}

1. Karavanaki K, Davies AG, Hunt LP, Morgan MH, Baum JD. Pupil size in diabetes. Arch Dis Child. 1994;71(6):511-5.

2. Pena MM, Donaghue KC, Fung AT, Bonney M, Schwingshandl J, Howard NJ, et al. The prospective assessment of autonomic nerve function by pupillometry in adolescents with type 1 diabetes mellitus. Diabet Med. 1995:12(10):868-73.

3. Schwingshandl J, Simpson JM, Donaghue K, Bonney MA, Howard NJ, Silink M. Pupillary abnormalities in type I diabetes occurring during adolescence. Comparisons with cardiovascular reflexes. Diabetes Care. 1993;16(4):630-3.

4. Boev AN, Fountas KN, Karampelas I, Boev C, Machinis TG, Feltes C, et al. Quantitative pupillometry: normative data in healthy pediatric volunteers. J Neurosurg. 2005;103(6 Suppl):496-500.

5. Taylor WR, Chen JW, Meltzer H, Gennarelli TA, Kelbch C, Knowlton S, et al. Quantitative pupillometry, a new technology: normative data and preliminary observations in patients with acute head injury. Technical note. J Neurosurg. 2003;98(1):205-13

6. Adhikari P, Zele AJ, Thomas R, Feigl B. Quadrant field Pupillometry detects Melanopsin dysfunction in Glaucoma suspects and early Glaucoma. Sci Rep. 2016;6:33373.

7. Feigl B, Zele AJ, Fader SM, Howes AN, Hughes CE, Jones KA, et al. The postillumination pupil response of melanopsin-expressing intrinsically photosensitive retinal ganglion cells in diabetes. Acta Ophthalmol. 2012 90(3):e230-4.

8. Kardon R, Anderson SC, Damarjian TG, Grace EM, Stone E, Kawasaki A. Chromatic pupillometry in patients with retinitis pigmentosa. Ophthalmology. 2011;118(2):376-81.

9. Meeker M, Du R, Bacchetti P, Privitera CM, Larson MD, Holland MC, et al. Pupil examination: validity and clinical utility of an automated pupillometer. J Neurosci Nurs. 2005;37(1):34-40.
10. Couret D, Boumaza D, Grisotto C, Triglia T, Pellegrini L, Ocquidant P, et al. Reliability of standard pupillometry practice in neurocritical care: an observational, double-blinded study. Crit Care. 2016;20:99.

11. Brown JT, Connelly M, Nickols C, Neville KA. Developmental changes of Normal pupil size and reactivity in children. J Pediatr Ophthalmol Strabismus. 2015;52(3):147-51.

12. Kohnen EM, Zubcov AA, Kohnen T. Scotopic pupil size in a normal pediatric population using infrared pupillometry. Graefes Arch Clin Exp Ophthalmol. 2004;242(1):18-23.

13. Harris PA, Taylor R, Thielke R, Payne J, Gonzalez N, Conde JG. Research electronic data capture (REDCap)--a metadata-driven methodology and workflow process for providing translational research informatics support. J Biomed Inform. 2009;42(2):377-81.

14. Fan X, Hearne L, Lei B, Miles JH, Takahashi N, Yao G. Weak gender effects on transient pupillary light reflex. Auton Neurosci. 2009;147(1-2):9-13.

15. Tekin K, Sekeroglu MA, Kiziltoprak H, Doguizi S, Inanc M, Yilmazbas P. Static and dynamic pupillometry data of healthy individuals. Clin Exp Optom. 2018;101(5):659-65.

16. Winn B, Whitaker D, Elliott DB, Phillips NJ. Factors affecting light-adapted pupil size in normal human subjects. Invest Ophthalmol Vis Sci. 1994;35(3): 1132-7.

17. Adhikari $P$, Zele AJ, Feigl B. The post-illumination pupil response (PIPR). Invest Ophthalmol Vis Sci. 2015;56(6):3838-49.

18. Kelbsch C, Strasser T, Chen Y, Feigl B, Gamlin PD, Kardon R, et al. Standards in Pupillography. Front Neurol. 2019;10:129.

19. Zele AJ, Feigl B, Smith SS, Markwell EL. The circadian response of intrinsically photosensitive retinal ganglion cells. PLoS One. 2011;6(3): e17860.

\section{Publisher's Note}

Springer Nature remains neutral with regard to jurisdictional claims in published maps and institutional affiliations.

Ready to submit your research? Choose BMC and benefit from:

- fast, convenient online submission

- thorough peer review by experienced researchers in your field

- rapid publication on acceptance

- support for research data, including large and complex data types

- gold Open Access which fosters wider collaboration and increased citations

- maximum visibility for your research: over $100 \mathrm{M}$ website views per year

At $\mathrm{BMC}$, research is always in progress.

Learn more biomedcentral.com/submissions 